\title{
Better to Exploit than to Neglect? International Clinical Research and the Non-Worseness Claim
}

Erik Malmqvist

The self-archived postprint version of this journal article is available at Linköping University Institutional Repository (DiVA):

http:/ / urn.kb.se/ resolve?urn=urn:nbn:se:liu:diva-140522

N.B.: When citing this work, cite the original publication.

Malmqvist, E., (2017), Better to Exploit than to Neglect? International Clinical Research and the Non-

Worseness Claim, J ournal of Applied Philosophy, 34(4), 474-488. https:// doi.org/ 10.1111/japp.12153

Original publication available at:

https:/ / doi.org/ 10.1111/japp.12153

Copyright: Wiley (24 months)

http:/ / eu.wiley.com/WileyCDA/ 


\title{
Better to Exploit than to Neglect? \\ International Clinical Research and the Non-Worseness Claim
}

\begin{abstract}
Author: Erik Malmqvist, Ph.D., Department of Thematic Studies: Technology and Social Change, Linköping University, Linköping University, SE-581 83 Linköping, Sweden. Email. erik.malmqvist@liu.se. Phone: +461328 23 32. Fax: +46132844 62.
\end{abstract}

\begin{abstract}
Clinical research is increasingly 'offshored' to developing countries, a practice that has generated considerable controversy. It has recently been argued that the prevailing ethical norms governing such research are deeply puzzling. On the one hand, sponsors are not required to offshore trials, even when participants in developing countries would benefit considerably from these trials. On the other hand, if sponsors do offshore, they are required not to exploit participants, even when the latter would benefit from and consent to exploitation. How, it is asked, can it be worse to exploit the global poor than to neglect them when exploitation is voluntary and makes them better off? The present paper seeks to respond to this challenge. I argue that mutually beneficial and voluntary exploitation can be worse than neglect when - as is typically true of exploitative research - it takes advantage of unjust background conditions. This is because, in such cases, exploitation overlaps with another, less familiar wrong: complicity in injustice. Recognising complicity as a distinct wrong should make us judge exchanges arising from background injustice more harshly than we typically do, in research and elsewhere.
\end{abstract}




\section{Introduction}

Before a new drug or medical intervention is permitted on the market its safety and efficacy must be established in clinical trials. A fast-growing proportion of these trials are conducted in developing countries. Powerful financial and scientific considerations motivate pharmaceutical firms and other sponsors to locate trials in these countries rather than at home. The costs of goods and services required for research are lower. Trials are believed to yield clearer results because participants are generally on fewer medications. And potential participants are more readily available, allowing trials to be completed more quickly, which in turn permits earlier marketing and larger returns. Also, by conducting trials sponsors may gain access to new and potentially large markets in host countries. These countries themselves are often eager to attract foreign sponsors, and have sometimes worked vigorously to do so as part of broader strategies of economic liberalization and international competitiveness. ${ }^{1}$ However, while perceived as advantageous by sponsors and host countries alike, the 'offshoring' of clinical research is ethically controversial and the subject of a heated, longstanding debate. ${ }^{2}$

Much of the debate has focused on particular trials or on specific questions about, for instance, benefit sharing, informed consent and trial design. But some issues go much deeper. Alan Wertheimer has recently argued that received wisdom on international research ethics, as expressed in ethical guidelines and in the writings of leading bioethicists, rests on unexamined but highly problematic assumptions. Among the difficulties he identifies is the following tension. On the one hand, even though individuals in the developing world may stand to benefit from offshored research, sponsors are not normally thought to have a duty to offshore. Few, if any, believe that it would be seriously wrong for them to conduct research in developed countries instead. On the other hand, if sponsors do offshore they are required not to exploit participants, even if the latter would benefit considerably from and 
voluntarily, even eagerly, submit to exploitation. Not only must participants benefit from and consent to research; non-exploitation requires the level of benefits to be sufficiently high. Taken together these views are puzzling, Wertheimer notes. If it is permissible not to make people in poor countries better off at all, by running trials at home instead, how can it be seriously wrong to make them somewhat better off, by running beneficial but exploitative trials? How can it be worse to exploit the global poor than to ignore their plight? ${ }^{3}$

This paper seeks to respond to this challenge. I shall argue that conducting mutually beneficial and voluntary exploitative research in developing countries can be worse than not interacting with these countries at all, on a sufficiently inclusive analysis of the ethical stakes of such research. The paper has the following structure. Section 2 considers Wertheimer's challenge in greater detail, while section 3 lays bare its theoretical underpinnings and situates my response to it. In sections 4 and 5 I articulate that response: exploitative research tends to involve a further wrong, complicity in structural injustice, and is therefore typically worse than commonly recognized. Section 6 concludes my argument and outlines its implications for future debates on exploitation and research ethics.

\section{The Problem}

Wertheimer's challenge only applies to voluntary and mutually beneficial research. There is nothing puzzling about the view that enrolling the global poor in medical experiments is worse than neglecting them if they fail to give valid consent or are likely to be harmed in consequence. I shall therefore restrict my discussion to cases where participants both consent to and stand to benefit from research, yet appear to be exploited. This may exclude many realworld instances of unethical research. ${ }^{4}$

Consider two simplified but realistic cases where the challenge does seem to apply. $^{5}$ 
Surfactant: Respiratory distress syndrome (RDS) is a breathing disorder commonly affecting premature infants. It is caused by insufficient surfactants in the lungs and is potentially fatal. Surfactant replacement therapy greatly reduces RDS mortality and is standard of care in developed countries. Such therapy is, however, too expensive to be widely available in many developing countries. A pharmaceutical firm wants to test a new synthetic surfactant in a randomized phase III trial. To obtain the best results at the lowest cost the firm prefers to use a placebo control. Aware that a placebo-controlled trial would not pass ethical review in countries where surfactant therapy is widely used, they decide to conduct the trial in Bolivia, where few infants have access to therapy. All participants will receive antibiotics and ventilator support. In addition, half of them will be randomly assigned to receive air infused with the surfactant through an endotracheal tube; the other half will receive untreated air. Parents of infants with RDS are carefully informed about the study and asked to give consent for their babies to participate. Many eagerly embrace the offer.

Breast Cancer: A pharmaceutical company wants to test the efficacy of two different doses of a new adjuvant therapy for advanced breast cancer that has shown great promise in earlier trials. To get quick and clear results they decide to run the trial in India, where potential participants are more readily available and more frequently untreated than in the West. Participants will be randomly assigned to receive either a higher or a lower dose of the drug for the duration of the trial. Due to limited funds the sponsor will not provide either group with any treatment after completing the trial. Other effective adjuvant therapies are available in India, but few breast cancer patients can afford them. Hundreds of women enrol in the trial in pursuit of an otherwise inaccessible form of treatment. They are carefully informed and consent to participating. 
It appears that participants stand to benefit from enrolling in these trials. Of course, there is an element of gamble. The tested treatment may turn out to be less effective than expected, or to have side effects that outweigh the benefits. But uncertainty about treatment effects is integral to clinical research and indeed what motivates (scientifically sound) trials in the first place. Whether participation is beneficial must therefore be assessed prospectively, anticipating potential outcomes at the outset of the trial, rather than retrospectively, with knowledge of the actual outcome on hand. ${ }^{6}$ Prospectively, enrolling in a trial of a treatment that previous studies suggest, albeit inconclusively, is safe and effective clearly seems better than not receiving any treatment at all. This is true even when the chance of receiving the treatment is only 50\% (as in Surfactant) and even when one will only receive it for a limited period of time (as in Breast Cancer).

It also appears that participants - or, in Surfactant, their parents - give valid consent. They are carefully informed about what participation entails and are not coerced or manipulated into accepting the sponsors’ offer. It might be argued that their acceptance is insufficiently voluntary because they lack other viable options: the trial is, after all, their only chance of obtaining a treatment that they or their children need. However, it is not clear that a lack of acceptable alternatives undermines voluntariness. It would seem that people can voluntarily consent to life saving medical treatment when the sole alternative is death, voluntarily accept offers of jobs they need in order to maintain an acceptable standard of living and so on. ${ }^{7}$

While consensual and mutually beneficial, both trials would likely strike many people as unethical. The worry here is more plausibly about exploitation than about harm or consent. Most exploitation theorists agree that even exchanges and relationships that are fully voluntary and benefit both parties can be wrongfully exploitative. ${ }^{8}$ And avoiding exploitation, 
including its voluntary and mutually beneficial forms, is commonly considered the underlying rationale for research ethical principles. ${ }^{9}$

But what, exactly, is it about these trials that triggers worries about exploitation? While different accounts of exploitation would provide different answers, the prevailing account in research ethics understands exploitation in terms of taking unfair advantage. ${ }^{10} \mathrm{On}$ this account, mutually beneficial transactions are wrongfully exploitative when their outcome is unfairly divided between the parties - when one party stands to benefit too much and the other too little from the point of view of fairness. Taken by itself this account is imprecise: a principle of fair distribution is needed to determine exactly when transactions are exploitative. Although such a principle has proved difficult to specify, ${ }^{11}$ the view that research participants can be unfairly taken advantage of even if they consent and benefit remains widely endorsed.

However imprecise, this view enables the following elaboration of the concerns about exploitation that trials like Surfactant and Breast Cancer raise. Even though the participants (or their parents) willingly accept the benefits the sponsors offer, these benefits are too small compared to the risks involved and the benefits to other parties. The sponsors owe them more. To avoid exploitation they must provide 'super-contractual' benefits benefits greater than those to which participants would otherwise have agreed. ${ }^{12}$

Demands for super-contractual benefits are encoded in influential international research ethical guidelines. For instance, the Declaration of Helsinki requires that subjects in the control arm of a trial receive the best established intervention, unless no such intervention exists or withholding it only risks causing minor harm, even when patients without access to care predictably would be willing to enrol in a placebo controlled trial. ${ }^{13}$ And so Surfactant is ruled out. Further, both Helsinki and the CIOMS guidelines require that participants get access to any intervention proved beneficial in a trial after the trial is over, even when they predictably would be willing to settle for access during the trial only. ${ }^{14}$ And so Breast Cancer 
is ruled out. Both requirements proscribe trials where participants might be inclined to agree to an unfairly low and hence, exploitative level of benefits.

Now suppose the sponsors in our cases, perhaps in response to charges of exploitation, abandon their plans to conduct trials in developing countries and decide to run differently designed trials in their home countries instead. How would that decision be evaluated? Research ethical guidelines and bioethicists do not say much explicitly. ${ }^{15}$ While the responsibilities of sponsors and investigators involved in offshored research have been abundantly discussed, the ethics of not offshoring remains largely unexamined. Of course, it is widely recognized that research in poor countries is urgently needed to address the specific health problems these countries face. But when it comes to diseases afflicting the global rich, or rich and poor alike, it is tacitly considered preferable or at least acceptable to locate research among the rich. Rarely, if ever, are Western sponsors criticized for conducting trials at home when they could have offshored instead. Even when offshored research meets established ethical and scientific standards, it tends to be regarded as permissible at best - not as a duty. So the decision not to run trials in Bolivia or India is unlikely to attract much moral censure, even though the trials represent the only chance for patients in these countries to receive the treatment they need.

What is puzzling about this set of views is this. When sponsors provide some benefits to needy people in developing countries we criticize them for not providing enough. We call them exploiters and demand that the benefits be greater. But when sponsors do nothing to benefit these people we do not criticize them at all. Assuming that the welfare of the sick and poor is our guiding concern, this discrepancy surely needs to be explained.

\section{The Non-Worseness Claim}


The problem is not unique to the ethics of international clinical research. In fact, anyone who believes that mutually advantageous and voluntary exploitation is seriously wrong faces it. Consider a different example. Sweatshops and the multinational firms they contract with are widely criticized for exploiting workers in poor countries, even though some of these workers, because they lack better options, may well voluntarily choose and benefit from sweatshop labour. ${ }^{16}$ In response to such criticism, Matt Zwolinski remarks:

The charge against firms is not that they are harming workers, but that the benefit they gain from the transaction is disproportionate to that gained by the workers. But the firms are doing something to help. The wages they pay to workers make those workers better off than they used to be...Do they have an obligation to do more? Consider the fact that most individuals do nothing to make Third-World workers better off. Are they blameworthy? As blameworthy as sweatshops?...[I]t would be odd to blame [firms] for helping some when we blame individuals less (or not at all) for helping none. ${ }^{17}$

More generally, the challenge can be expressed in terms of what exploitation theorists call the non-worseness claim: 'it cannot be morally worse for A to interact with B than not to interact with B if: (1) the interaction is better for B than non-interaction, (2) B consents to the interaction, (3) such interaction has no negative effects on others' ${ }^{18}$ The non-worseness claim maintains, then, that voluntary and mutually beneficial exploitation without negative externalities cannot be worse than neglect. It thus contradicts ordinary moral views, which tend to condemn exploitation more harshly than neglect, but in a way that upon reflection may appear almost incontrovertible. Can it really be worse to benefit somebody than not to benefit her provided that she consents and that others are unaffected? 
If the non-worseness claim is true, our views require revision in either of two opposing directions. ${ }^{19}$ Either we continue holding that neglect is not especially wrong, but accept that exploitation is much more innocent than we thought. Or we continue holding that exploitation is seriously wrong, but accept that neglect is much worse than we thought. In the research context, the first response recommends a considerable relaxation of prevailing ethical standards: exploitative research should no longer be condemned when participants benefit and consent. The second response, by contrast, recommends a considerable strengthening of these standards: it is not just admirable but morally required for sponsors to conduct beneficial (and non-exploitative) research among the global poor. Staying home is indefensible. Which response one favours will depend on one's views on the broader question where the responsibility for remedying health problems in poor countries lies: with sponsors, local governments, international organizations, affluent states or some other agent. ${ }^{20}$ The first response denies that sponsors have a special duty in this regard; the second response affirms that they do.

A third possible response, of course, is to deny the truth of the non-worseness claim. For instance, some have argued that exploitation can be worse than neglect, even when it is voluntary and better for its victims, because it is demeaning or degrading in a way that neglect is not. ${ }^{21}$ If some such response successfully rejects the non-worseness claim, it might vindicate the prevailing tendency to both condemn exploitative research in the developing world and tolerate the failure to do research there at all. ${ }^{22}$

My response is different. I shall not take sides on the large and thorny question of who is ultimately responsible for fulfilling the health needs of the global poor. Nor shall I seek to outright reject the non-worseness claim. Rather, I want to question its scope. I suspect that it often does not apply to international research. In much such research the three conditionals in the above rendering of the non-worseness claim fail to jointly hold. Now we 
have already granted (1) and (2): we are concerned exclusively with mutually beneficial and voluntary interaction. We should not, however, grant (3). Effects on third parties cannot be legitimately bracketed when morally assessing international research. ${ }^{23}$ When exploitative, such research also tends to be guilty of a distinct but less familiar wrong, which does affect parties beyond the exchange, thus deepening its badness. This wrong is best described as complicity in the broader injustices that constitute the backdrop of exploitation. ${ }^{24}$

\section{Exploitation and Background Injustice}

There is little doubt that offshored research evokes unease partly because of the precarious structural conditions in which it is carried out. Many popular destinations for such research have large populations that are poor and lack access to well-functioning healthcare services, and participants appear to be recruited in large part from precisely such populations. ${ }^{25}$ The circumstances of these participants raise two sorts of concern that should be carefully distinguished; one is easily accommodated by exploitation theory, the other is not.

First, poverty and lack of access to healthcare make people vulnerable to exploitation. Such circumstances easily weaken one's bargaining position to such an extent that one cannot reasonably turn down unfair, but beneficial offers. This is arguably the case in Surfactant and Breast Cancer: lacking other ways of improving their situation, participants eagerly embrace the significant yet unfairly small improvement offered by the sponsors.

The second concern is that these background circumstances are themselves unjust. While different conceptions of domestic and global justice disagree about how much healthcare and economic security individuals have a claim to, and against whom, most reasonable conceptions agree that justice requires access to at least some minimum level of these goods. ${ }^{26}$ One need not commit to any particularly extravagant conception of justice in general or just healthcare in particular to find the inaccessibility of drugs among participants 
in Surfactant and Breast Cancer unjust. The drugs they lack are no luxuries. The WHO lists surfactants and certain drugs used for adjuvant breast cancer therapy as essential medicines. ${ }^{27}$ This means that they are thought to satisfy priority healthcare needs, and that access to them is considered part of the human right to health. And the unavailability of these and other drugs in poor countries is no immutable natural fact, but at least partly the foreseeable and avoidable consequence of international agreements shaped by the governments of rich countries to favour these countries' interests. ${ }^{28}$

In view of these considerations, the inaccessibility of surfactants and adjuvant therapy that leads people to enrol in research in our cases may plausibly be considered unjust rather than merely unfortunate. Moreover, since participants would not agree to participate on the sponsors' terms in just circumstances - if they had access to these treatments - the sponsors can rightly be said to take advantage of injustice.

The prevailing view of exploitation in research brackets this latter concern. On this view, recall, exploitation is a feature of discrete exchanges. Whether an exchange is exploitative depends solely on the terms of that exchange - on their fairness or unfairness not on any feature of the broader circumstances where it occurs. Transactional or 'micro' fairness is strictly independent of fairness or justice on the structural or 'macro' level. ${ }^{29}$ The fact that the sponsors in our cases take advantage of injustice by using the local unavailability of treatments to recruit participants is ultimately irrelevant for determining whether they also take unfair advantage of these participants, i.e. exploit them. ${ }^{30}$ Researchers and sponsors committed to avoiding exploitation should ensure that they interact with participants on fair terms, not worry about broader questions of social justice.

This narrow focus on transactional fairness has not gone unchallenged. Alternative accounts of exploitation have been proposed and applied to the case of international research. ${ }^{31}$ On these accounts, background injustices cannot be bracketed when 
determining whether transactions are exploitative. At least some forms of exploitation consist in taking advantage of pre-existing unjust social arrangements. And so researchers and sponsors cannot disregard such broader injustices if they want to avoid exploiting participants.

Whether or not such alternative accounts are ultimately convincing, it is not clear that research ethics needs them. We need not redefine exploitation to explain why background injustices are directly ethically relevant to the interaction between sponsors/researchers and participants. More modestly, we may stick to the standard transactional view, but recognize that exploitation coexists with a distinct wrong when it preys on injustice. To take advantage of structural injustice, in research and elsewhere, is to become complicit in its reproduction. ${ }^{32}$ In what follows, I shall first characterize complicity in general terms, before turning to complicity in international research, and finally to how recognizing complicity allows us to respond to the non-worseness claim.

\section{Complicity}

\subsection{A Conceptual Outline}

To be complicit is, generally speaking, to be involved with others in some wrongdoing and thereby share responsibility for it. A weapons dealer may be complicit in a murder committed with a gun he has sold; a multinational apparel retailer may be complicit in human rights violations perpetrated by its subcontractors; a physician may be complicit in torture by patching up its victim enough to sustain another beating. And research sponsors may be complicit in unjust inaccessibility of healthcare if they take advantage of that injustice to recruit subjects - or so I shall argue.

Chiara Lepora and Robert E. Goodin have recently proposed a general theory of complicity, which, slightly modified in a way I shall explain shortly, suits present purposes 
well. ${ }^{33}$ This account understands complicity as, roughly, contributing knowingly to the wrongful actions of others. A few words on each element in this phrase are in order.

'Contributing' means ‘contributing causally’. Agents cannot be complicit in wrongdoing unless they bear some causal relationship to it. This condition might appear to run into familiar overdetermination problems. The weapons dealer makes no causal difference to the commission of a murder if somebody else would have provided the killer with the gun had he refused. However, we should not ask whether, retrospectively, agents actually did make a difference to the bad outcome, but instead whether, prospectively, they might potentially make a difference. Because morality is supposed to be action guiding, moral assessment should, as Lepora and Goodin argue, adopt the forward-looking perspective of agents. ${ }^{34}$ From this perspective it seems that the weapons dealer might indeed, for all he knows, make a difference to the commission of the murder.

Some believe that complicity requires intentionally participating with wrongdoers in the pursuit of some shared end. ${ }^{35}$ But that seems too strong. The weapons dealer may not at all intend the realization of the killer's plan, but only seek to make money. Yet if he is aware of the plan and that his gun is needed to carry it out he appears complicit nonetheless. Rather than shared intentions, complicity requires that one knows, or could and should have known, that one's action contributes to wrongdoing. ${ }^{36}$ If the dealer has no reason whatever to suspect that his gun will be used in a murder he shares no responsibility for it. But note that ignorance must itself be faultless to cancel responsibility. If the dealer carelessly sells guns to anyone or overlooks the prospective killer's obvious aggressiveness he is complicit despite his ignorance.

Crucial to Lepora and Goodin's account is the distinction between 'principals' (e.g. the torturer) and 'secondary agents' (e.g. the physician). Only the latter can be complicit, they hold, because only they contribute to wrongdoing; the actions of the former constitute 
it. ${ }^{37}$ However, this distinction may be incapable of handling the special case of complicity in structural injustices. Iris Marion Young claims that, unlike other wrongs, such injustices cannot be attributed to any single agent. Rather, she plausibly argues, they are produced by large numbers of agents each pursuing their own ends without anyone playing any special role in their commission. ${ }^{38}$ I shall therefore adopt a more inclusive view, on which agents can be complicit not only by contributing to wrongs committed by principals, but also by playing a causal role in wrongs committed by unorganized collectives lacking principals. ${ }^{39}$

Contributing to wrongdoing is itself pro tanto wrong. How blameworthy it is depends on several factors, including the badness of the act one contributes to, the probability of making a difference to it, and the magnitude of that difference. ${ }^{40}$ Like other pro tanto wrongs, complicit actions may be on balance justified. Treating a torture victim may make a physician complicit in torture, but it may still be the right thing to do if it is necessary to save the victim's life. And the usual conditions that excuse wrongdoing - such as involuntariness may apply here too. ${ }^{41}$ The physician may be unable to justify her involvement in torture by invoking some greater good, but still be exempt from blame if she participates at gunpoint.

\subsection{Complicity in International Research}

With this background in place, let us now return to the ethics of international research. I have argued that in cases like Surfactant and Breast Cancer the sponsors take advantage of participants' unjust lack of access to healthcare. How might such advantage taking make them complicit, in the causal sense specified above, in that injustice?

One way to potentially contribute to structural injustices by taking advantage of them is by creating incentives to slow structural reform. ${ }^{42}$ Research sponsors already have an interest in continued lack of access to healthcare in poor countries because that situation presents opportunities to run future research on terms highly favourable to them. If people had 
adequate access to care, they would not enrol in trials like Surfactant and Breast Cancer, and trials would have to be designed in costlier ways. However, once such trials are initiated this interest is amplified. If potential participants then gain access to needed treatment, trials have to be redesigned or relocated in midstream. Either way, a large investment is lost. Sponsors with a trial underway thus have an especially strong reason to prefer that treatment remain inaccessible for the duration of the trial (typically months or years). Indeed, they have reason to actively oppose efforts to increase access if they can do so effectively. It is worth noting here that drug companies have considerable economic and legal muscles, and are known to have greatly influenced policy-making in the past. ${ }^{43}$ If they conduct trials in ways that depend on unjust inaccessibility of care they give themselves an incentive, in addition to the one they already have, to exercise their influence to preserve that injustice.

It might be objected that merely creating such an incentive is not sufficient to make sponsors complicit unless they actually act on it. Recall, however, that to determine whether agents are complicit we should adopt the forward-looking perspective of the agents themselves. Complicity does not require that an agent actually has contributed to wrongdoing, retrospectively. It is sufficient that she, prospectively, (knowingly or culpably negligently) might potentially contribute with a certain probability. It follows that just like one should avoid participating in wrongdoing directly, so too should one avoid putting oneself in a position where one foresees, or should foresee, finding such participation difficult to resist. For putting oneself in such a position is also to potentially contribute to the wrongdoing, to make its future occurrence more likely. Thus, it is wrong for sponsors not only to oppose attempts to improve access to treatments in the developing world, ${ }^{44}$ but also to give themselves a powerful incentive for such opposition by using the current insufficient access to conduct research on terms advantageous to themselves. They are complicit in that injustice even if that incentive never actually prompts them to act. 
By taking advantage of a structural injustice the sponsors in our cases give not only themselves, but also other parties, incentives to resist structural reform. After all, many others have a stake in the research. The purpose of (legitimate) clinical trials is to help patients by developing interventions that are in some respect better - more effective, safer, cheaper or more practicable - than the established ones. And the host countries, too, expect to gain. Whether or not the sponsors are willing to share the fruits of the research with these countries, simply carrying it out is likely to involve providing benefits like improved care infrastructure, job opportunities and tax revenues. ${ }^{45}$ In themselves, such third-party benefits are of course to be welcomed. The problem, in cases like Surfactant and Breast Cancer, is that they are contingent on people’s unjust lack of access to healthcare. While such trials are being conduced, policy-makers - both in the host country and abroad - may be unwilling to address that injustice, because that may jeopardize the weighty benefits they expect from the trials.

Taking advantage of injustice risks contributing to its reproduction in another way. When researchers enrol people without access to adequate healthcare they come into immediate contact with a conspicuous injustice. The participants facing them are entitled to a level of care that they are not receiving. The researchers (together with their sponsors) have the competence, resources and opportunity to provide that care, but the trial design requires them not to provide it. Now it might be thought that the sheer failure to correct an injustice one can correct counts as contributing causally to it. After all, omissions are sometimes regarded as causes for purposes of attributing responsibility. A parent may for instance be held responsible for causing his child harm by neglecting its needs. But note that there may be others - neighbours, say - who could also fulfil the child's needs, but whose failure to do so would not be considered culpably negligent. Omissions are ubiquitous and not all constitute grounds for responsibility. When they do it is typically because they involve shirking some duty. The parent's omission, unlike that of the neighbours, is thought to cause the child harm 
because only he has a duty to look after the child. Returning to our cases, we have left the question open whether researchers or sponsors have a pre-existing duty to provide treatments for the global poor. Without assuming that there is such a duty, their failure to provide treatment cannot be classified as a contribution-by-omission to injustice.

But that failure should count as a potential contribution to injustice by virtue of its expressive effects. Turning injustice into profit legitimizes similar behaviour on the part of others similarly placed. In our cases, the sponsors send the message to other research sponsors that they too may conduct trials that involve withholding treatments to which participants are entitled. And these other sponsors are then more likely to run such trials, thus creating incentives for themselves and others to resists improving access to treatments in the ways described above. Interestingly, the participants themselves may contribute to the message that is being sent. The fact that they voluntarily agree to the exchange lends it an air of legitimacy. Their voluntariness serves as a 'surface endorsement' of the sponsors' offer, effectively muting protest against it. ${ }^{46}$ Demands for larger benefits will easily appear excessive since the benefits on offer are so eagerly embraced. And such demands will be more readily dismissed in the future.

The message sent to other parties might be even more troubling. It may or may not ultimately be the sponsors' duty to provide the care that the global poor are unjustly denied. But surely somebody has such a duty. Deliberately withholding care that participants are entitled to easily communicates to those who are responsible for providing care that they too may withhold it. It gives them a fig leaf behind which to hide their own failure to act. These parties are tempted to ask: if big pharma, despite the skills and resources they command, do not provide care when they could, then why should we? Or: if medical researchers, motivated as they are by concern for health and welfare, do not do more for these 
people, then can their suffering be so bad? Thus, through the expressive meaning of their act, the sponsors risk contributing to the continuing neglect of unjust ill health.

Now potentially contributing to injustice is not enough to be complicit in it. As mentioned, one must also be aware or culpably ignorant of one’s potential contribution. Suppose our imagined sponsors claimed that we cannot reasonably expect them to know that their practices help perpetuating unjust lack of access to healthcare. Would they be right? As to the effects of their conduct on incentives to slow structural reform, such a defence would seem at least somewhat disingenuous. The lack of access to care in developing countries is no secret; indeed, it is widely recognized as a key reason for offshoring research to these countries, including by the industry itself. ${ }^{47}$ Nor does it take very much self-scrutiny on the sponsors’ part to realize that they have reason to prefer that situation to persist when their research depends on it and, if possible, to act on that preference. Surely we expect such accomplished competitors to know by and large where their own interests lie.

The ignorance defence gains plausibility if we turn to the expressive effects of the sponsors' conduct. Agents cannot be expected to foresee all possible ways that others might interpret what they do. However, the agents in question are unusually circumspect about such interpretations. Like other large businesses, pharmaceutical firms tend to be highly sensitive about their public image and to invest considerably in cultivating it. It is not unreasonable, therefore, to expect them to foresee that their decision to withhold treatment they could provide might send a disturbing message. After all, that message - essentially that other agents may also withhold treatment - is not particularly far-fetched.

What if our sponsors claimed ignorance not of their potential contribution to the current situation of healthcare in developing countries, but of that situation's status as unjust? ${ }^{48}$ There would be something disingenuous about such a response too. The pharmaceutical industry vigorously invokes the moral imperative of expanding the treatment 
options available to patients as the key rationale for their activities. ${ }^{49}$ It would be blatantly inconsistent to deny that this imperative extends a fortiori to developing countries, where options are much more limited.

Other things being equal, complicity should be avoided. To avoid complicity in structural injustice one must refrain from taking advantage of it when interacting with its victims. This requires interacting on terms they would accept if background conditions were just. ${ }^{50}$ In Surfactant, the sponsors should test their drug against an existing surfactant therapy instead of placebo. In Breast Cancer, they should provide post-trial access to an adjuvant treatment at least as good as the treatment breast cancer patients would ordinarily receive in a just Indian healthcare system. ${ }^{51}$ By offering terms that participants might accept if they had fair access to care, the sponsors would not rely on their current insufficient access to conduct research. They would therefore not create any incentive to preserve that injustice. Nor would they send the message that those responsible for reform need not act. Indeed, they would arguably send the opposite message: the status quo is unacceptable and demands redress.

Other things might not be equal, of course. While pro tanto wrongful, complicit research can be on balance justified by the benefits it might bring to participants, host communities or future patients. However, justifying complicity in this way is harder than one might think. Not only must the good appealed to be a weighty one. It must also be unattainable without incurring complicity or doing something even worse. ${ }^{52}$ An undercover cop may be justified in participating in a crime if it is necessary to gain a criminal gang's trust and obtain information required for an arrest, but not if she could gain that information without participating. Likewise, sponsors may be justified in taking advantage of unjustly deficient healthcare if they cannot otherwise conduct some truly important study, but not if they could conduct the study without such advantage-taking. Sometimes relying on poor people's lack of access to care might be an unavoidable feature of research aiming at 
improving access to care in their community. ${ }^{53}$ Here complicity may be considered a necessary evil. But in many other cases, including Surfactant and Breast Cancer, complicity cannot be so considered. This is because the benefits from research could be realized without complicity: by using an active control (Surfactant) or providing post-trial access to treatment (Breast Cancer).

\section{Conclusion}

Return to the puzzle with which we began. It seems strange to blame research sponsors for exploiting people in developing countries when these people consent to and benefit from the research, but not to blame sponsors when they do nothing to benefit the global poor. This strangeness is reduced if we adopt, as I suggest we do, a broad enough view of exploitative international research. In addition to exploiting participants, such research risks aggravating the broader injustices that frame the interaction. It is therefore worse than commonly recognized, and possibly worse than not conducting research in developing countries at all.

More generally, the upshot of my argument is this. When preying on structural injustice, exploiters should not be assumed to leave the world outside the individual exchange unaltered. They potentially contribute to the unjust circumstances they take advantage of, and are thus guilty of a distinct wrong: complicity. Because it potentially affects third parties negatively, exploitation that arises from structural injustice can be worse than neglect even when it is better for its victims and proceeds with their consent. Here the non-worseness claim, whether true or not, fails to apply.

None of this entails that exploiting victims of injustice is always worse than neglecting them, in international research or elsewhere. Although I have bracketed the question whether sponsors may legitimately disregard the healthcare needs of the global poor, my analysis is compatible with harshly condemning such disregard. On such a view, it is 
possible that the badness of neglect sometimes outweighs that of exploitation plus complicity. Thus it may be the case that research ethical standards should be strengthened to positively require sponsors to conduct research that benefits developing countries. But even on the widespread opposite view, that sponsors have no duty to interact with the global poor at all, exploiting them remains seriously wrong - even when they consent and benefit. No relaxation of ethical standards is required even on this view.

Two implications of my analysis are worth noting. First, while focused on international research, its relevance is much broader. Recognizing complicity as distinct wrong alongside exploitation should affect our evaluation of exchanges that take advantage of structural injustices quite generally. In research, such exchanges may occur also when trials are conducted in developed countries, for instance when subjects unjustly lack health insurance or access to basic social protection. ${ }^{54}$ Outside of research, they are likely to occur in many different practices, such as organ trade, prostitution, commercial surrogacy and sweatshop (and other) labour. The morally complex nature of such exchanges calls for further examination.

Second, my analysis gives some reason to worry about the current status of nonexploitation as the organizing research ethical principle. As typically understood in this context, exploitation is exclusively about the distributional pattern within a discrete two-party exchange. Such patterns may be deeply problematic, of course. But the world outside the exchange may be just as disturbing, and the exchange itself may contribute to making it so. Research ethics risks systematically overlook such concerns unless it broadens its conceptual repertoire. ${ }^{55}$ 


\section{NOTES}

${ }^{1}$ Adriana Petryna, When Experiments Travel: Clinical Trials and the Global Search for Human Subjects (Princeton: Princeton University Press, 2009); Melinda Cooper and Catherine Waldby, Clinical Labor: Tissue Donors and Research Subjects in the Global Bioeconomy (Durham: Duke University Press, 2014).

${ }^{2}$ Notable contributions to this debate include Ruth Macklin, Double Standards in Medical Research in Developing Countries (Cambridge: Cambridge University Press, 2004); Jennifer S. Hawkins and Ezekiel J. Emanuel (eds), Exploitation and Developing Countries: The Ethics of Clinical Research (Princeton: Princeton University Press, 2008); Angela J. Ballantyne, 'How to do research fairly in an unjust world', American Journal of Bioethics 10,6 (2010): 2635; Jeremy Snyder, 'Exploitations and their complications: The necessity of identifying the multiple forms of exploitation in pharmaceutical trials', Bioethics 26 (2012): 251-258; Vida Panitch, 'Exploitation, justice, and parity in international clinical research', Journal of Applied Philosophy 30 (2013): 304-318.

${ }^{3}$ Alan Wertheimer, Rethinking the Ethics of Clinical Research: Widening the Lens (Oxford: Oxford University Press, 2011); Alan Wertheimer, ‘The obligations of researchers amidst injustice or deprivation’ in J. Millum and E. J. Emanuel (eds), Global Justice and Bioethics (Oxford: Oxford University Press, 2012), pp. 279-304. I frame the puzzle as a tension between the permissibility of neglect and the duty not to exploit, rather than (as Wertheimer does in his work on clinical research) a tension between the permissibility of neglect and a broader duty to provide 'super-contractual' benefits. The framing I adopt seems to be the conventional one in the general literature on exploitation, where the puzzle has been most extensively discussed. See Alan Wertheimer, Exploitation (Princeton: Princeton University Press, 1996); Ruth J. Sample, Exploitation: What It Is and Why It's Wrong (Lanham: Rowman \& Littlefield, 2003); Matt Zwolinski, 'Sweatshops, choice, and exploitation’, 
Business Ethics Quarterly 17 (2007): 689-727; Matt Zwolinski, ‘Structural exploitation’, Social Philosophy and Policy 29 (2012): 154-179; Jeremy Snyder, 'Needs exploitation', Ethical Theory and Moral Practice 11 (2008): 389-405; Jeremy Snyder, 'Exploitation and demeaning choices’, Politics, Philosophy and Economics 12 (2013): 345-360.

${ }^{4}$ In several documented cases it seems clear that participants in offshored trials have been severely harmed and/or enrolled without providing valid consent. See e.g. Khabir Ahmad, 'Drug company sued over research trial in Nigeria', Lancet 358 (2001): 815. To the extent that research ethical protections seek to prevent such transgressions, they are not vulnerable to Wertheimer's challenge.

${ }^{5}$ The first case closely resembles the much-discussed Surfaxin trial, which was proposed in 2000 but never actually carried out. For discussions of this trial, see e.g. Macklin op. cit.; Hawkins and Emanuel op. cit.; Wertheimer 2011, 2012 op. cit.; Panitch op. cit. The second case closely resembles a trial described in a report from the Mumbai based Centre for Studies in Ethics and Rights. See Sandhya Srinivasan, Ethical Concerns in Clinical Trials in India: An Investigation (Mumbai: Centre for Studies in Ethics and Rights, 2009).

${ }^{6}$ Annette Rid and David Wendler, 'Risk-benefit assessment in medical research-critical review and open questions', Law, Probability and Risk 9 (2010): 151-157, at p. 153.

${ }^{7}$ Martin Wilkinson and Andrew Moore, 'Inducement in research’, Bioethics 11 (1997): 373389, at p. 377.

${ }^{8}$ Joel Feinberg, Harmless Wrongdoing (Oxford: Oxford University Press, 1990); Alan Wertheimer 1996 op. cit.; Sample op. cit.

${ }^{9}$ Ezekiel J. Emanuel et al., 'What makes clinical research ethical?' Journal of the American Medical Association 283 (2000): 2701-2711.

${ }^{10}$ Wertheimer 1996 op. cit. 
${ }^{11}$ Wertheimer himself, whose fairness-based theory frames the entire debate about exploitation in research, admits to being unable to find a 'non-problematic' principle of fairness after having carefully considered several candidates. See Wertheimer op. cit. 2011, pp. 206-211. Others have proposed such principles for the research context, which differ widely in their theoretical rationales and practical implications. See Ballantyne op. cit.; Panitch op. cit.; Participants in the 2001 Conference on Ethical Aspects of Research in Developing Countries, 'Moral standards for research in developing countries: From “reasonable availability” to “fair benefits”, Hastings Center Report 34,3 (2004): 17-27. There is no need to defend any particular principle of fairness here. The puzzle that I examine arises for any principle, including all those cited above, that requires providing 'supercontractual' benefits (defined below) for exploitation to be avoided. For any such principle entails that exploitation can benefit its victims, which invites doubts about its badness.

12 Wertheimer 2011 op. cit., p. 256.

${ }^{13}$ World Medical Association, Declaration of Helsinki: Ethical Principles for Medical Research Involving Human Subjects, §33. Available at: http://www.wma.net/en/30publications/10policies/b3/ (accessed 24 February 2015). While containing controversial provisions and lacking legislative force, the Declaration is an influential document. It has been incorporated into national legislation and is consulted by ethics review committees in many countries. See Richard E. Ashcroft, 'The Declaration of Helsinki' in E. J. Emanuel et al. (eds) The Oxford Textbook of Clinical Research Ethics (Oxford: Oxford University Press, 2008), pp. 141-148.

${ }^{14}$ World Medical Association op. cit., §34; Council for International Organizations of Medical Sciences, International Ethical Guidelines for Biomedical Research Involving Human Subjects (CIOMS: Geneva, 2002), guideline 10. The CIOMS guidelines were elaborated in 
collaboration with the WHO and mainly concern the implementation of the Helsinki Declaration.

${ }^{15}$ Both Helsinki and CIOMS are silent on this issue, for instance.

${ }^{16}$ I am certainly not assuming that sweatshop labour is always or typically freely chosen and beneficial to workers, only that it can be in some cases.

${ }^{17}$ Zwolinski 2007 op. cit., pp. 707-708 (emphasis in original).

${ }^{18}$ Zwolinski 2007 op. cit., p. 708. The claim was originally named and discussed in Wertheimer 1996 op. cit., pp. 289-293.

${ }^{19}$ Wertheimer 2011 op. cit., p. 259; Zwolinski 2012 op. cit., p. 168.

${ }^{20}$ Competing views on this issue are explored in Christian Barry and Kate Raworth, 'Access to medicines and the rhetoric of responsibility', Ethics and International Affairs 16,2 (2002): $57-70$.

${ }^{21}$ Sample op. cit.; Snyder 2013 op. cit.

${ }^{22}$ I say 'if' because a long range of attempts to reject the non-worseness claim (including the one mentioned here) have been rigorously examined and rebutted. See Wertheimer 2011 op. cit., pp. 289-309; Wertheimer 2012 op. cit., pp. 297-300; Zwolinski 2007 op. cit., pp. 708-710; Zwolinski 2012 op. cit., pp. 167-169.

${ }^{23}$ Wertheimer (2011 op. cit.) grants that the non-worseness claim only applies when an interaction lacks negative third-party effects. While he considers such effects briefly, in the research context (285-287) and generally (303), he seems to assume throughout most of his extensive discussion of the non-worseness claim that they can be legitimately bracketed. ${ }^{24}$ My argument seeks to defend research ethical norms against the non-worseness claim, not against other possible challenges. Wertheimer (2011, 2012 op. cit) argues that justifying these norms requires not only dismissing that claim, but also defending the 'greater obligation claim,' which says that 'among the potential beneficiaries of A's actions or resources, A has 
greater obligations to provide super-contractual benefits to B than to others, even though B has already benefited from interaction with A whereas others have received no benefit from A.’ See Wertheimer 2011 op. cit., p. 257. Since I am concerned only with the first of these claims I provide only a partial response to Wertheimer’s powerful challenge against research ethical norms.

${ }^{25}$ Cooper and Waldby op. cit.

${ }^{26}$ Joseph Millum, 'Global bioethics and political theory’, in Millum and Emanuel op. cit., pp. 17-42.

${ }^{27}$ Both are on the Model List and the national lists for Bolivia and India, respectively. See http://www.who.int/medicines/publications/essentialmedicines/en/index.html; http://www.who.int/selection_medicines/country_lists/bol/en/; and http://www.who.int/selection_medicines/country_lists/India_NLME_2011.pdf?ua=1 (all accessed 24 February 2015).

${ }^{28}$ In particular the Trade-Related Aspects of Intellectual Property Rights agreement, which standardizes intellectual property rights protection, including pharmaceutical patents, across WTO member states. See e.g. Thomas Pogge, World Poverty and Human Rights, $2^{\text {nd }}$ ed. (Cambridge: Polity Press, 2008)

${ }^{29}$ I borrow the terms ‘micro’ and ‘macro’ fairness from Jeremy Snyder (2012 op. cit.). ${ }^{30}$ The distinction between taking advantage of unfairness and taking unfair advantage was introduced by Wertheimer (1996 op. cit., pp. 298-299)

${ }^{31}$ For alternative general accounts of exploitation, see Sample op. cit.; Snyder 2013 op. cit. For alternative accounts of exploitation in research, see Snyder 2012 op. cit.; Agomoni Ganguli Mitra, 'Off-shoring clinical research: Exploitation and the reciprocity constraint', Developing World Bioethics 13 (2013): 111-118. In a recent paper in this journal, Vida Panitch (op. cit.) seeks to take concerns about background injustice into consideration by 
incorporating them into the transactional view of exploitation rather than by developing an alternative view. I share her ambition of making research ethics more sensitive to such concerns without abandoning that view of exploitation, but take a different route to that end. 32 Erik Malmqvist, ‘Taking advantage of injustice’, Social Theory and Practice 34 (2013): 557-580.

${ }^{33}$ Chiara Lepora and Robert E. Goodin, On Complicity and Compromise (Oxford: Oxford University Press, 2013).

${ }^{34}$ Lepora and Goodin op. cit., pp. 61-62

${ }^{35}$ Christopher Kutz, Complicity: Ethics and Law for a Collective Age (Cambridge: Cambridge University Press, 2000).

${ }^{36}$ Lepora and Goodin op. cit., pp. 80-83.

${ }^{37}$ Lepora and Goodin op. cit.

${ }^{38}$ Iris Marion Young, Responsibility for Justice (Oxford: Oxford University Press, 2011).

${ }^{39}$ Organized groups, such as companies, professional associations and churches, can themselves be treated as moral agents and thus as principals. See Philip Pettit, 'Responsibility incorporated', Ethics 117 (2007): 171-201. However, it is doubtful that the same can be said about wholly unorganized collectives.

${ }^{40}$ Lepora and Goodin op. cit., pp. 102-112.

${ }^{41}$ Lepora and Goodin op. cit., pp. 94-96.

${ }^{42}$ Malmqvist op. cit., pp. 572-574.

${ }^{43}$ Marcia Angell, The Truth About the Drug Companies: How They Deceive Us and What to Do About It (New York: Random House, 2004).

${ }^{44}$ As the pharmaceutical industry infamously did in the early 2000s by waging a legal battle against South Africa’s efforts to make available cheap HIV/AIDS drugs for its population. See Angell op. cit. 
${ }^{45}$ Petryna op. cit.

${ }^{46}$ On surface endorsement, see Snyder 2013 op. cit.

${ }^{47}$ In the words of one company that manages trials for global sponsors in India: 'A huge population with a diversity of diseases that are untreated - yes, that is the "India Advantage"”. Quoted in Wertheimer 2011 op. cit., p. 192. See also the consulting firm A. T. Kearney’s 2006 report, Make Your Move: Taking Clinical Trials to the Best Location. Available at: http://www.atkearney.com/health/ideas-insights/article//asset_publisher/LCcgOeS4t85g/content/make-your-move/10192 (accessed 24 February 2015).

${ }^{48}$ Agents may be blamelessly ignorant of contributing to wrongdoing either because they are unaware that they contribute or because they are unaware that what they contribute to is wrong. See Lepora and Goodin op. cit. p. 143.

${ }^{49}$ This discourse is for instance found all over the website of the Pharmaceutical Research and Manufacturers of America, the US pharmaceutical industry’s trade organization (http://www.phrma.org/about, accessed 24 February 2015).

${ }^{50}$ Malmqvist op. cit.

${ }^{51}$ Benefits to participants suffice to avoid the form of complicity I discuss here. However, sponsors may certainly, for other reasons, have duties to make drugs more widely available in the participants' communities. These duties may be seen as compensation for past complicity in these communities' poor access to healthcare, or defended on grounds unrelated to complicity, or both.

${ }^{52}$ Lepora and Goodin op. cit., pp. 123-124, 172.

53 This was possibly the case in the controversial maternal-fetal HIV transmission trials in the 1990s. These trials aimed to develop a treatment regime that was affordable and feasible for developing countries. Some of their defenders claimed that the only scientifically valid 
approach was to test the regime against placebo rather than the costly and complicated regime used in affluent countries at the time. For an overview of the controversy, see Macklin op. cit. ${ }^{54}$ Christine Pace, et al., 'Enrolling the uninsured in clinical trials: An ethical perspective', Critical Care Medicine 31 (2003): S121-125; Tom L. Beauchamp et al., 'Pharmaceutical research involving the homeless', Journal of Medicine and Philosophy 27 (2002): 547-564.

${ }^{55}$ A first version of this paper was written during a residency at the Brocher Foundation, Geneva, Switzerland, whose support I gratefully acknowledge. I also thank Martin Andersson, Isra Black and two anonymous referees for this journal for comments that helped me improve the paper. 